\title{
The effect of preoperative keratometry on visual outcomes after moderate myopic LASIK
}

This article was published in the following Dove Press journal:

Clinical Ophthalmology

20 March 2012

Number of times this article has been viewed

\section{Steven M Christiansen' \\ Marcus C Neuffer' \\ Shameema Sikder ${ }^{2}$ \\ Rodmehr T Semnani' \\ Majid Moshirfar'}

'John A Moran Eye Center, University of Utah, Salt Lake City, UT, ${ }^{2}$ Wilmer Eye Institute, Johns Hopkins

University, Baltimore, MA, USA

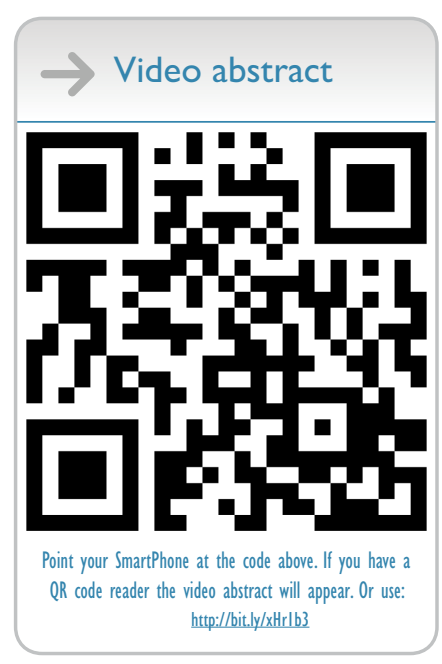

Correspondence: Majid Moshirfar 65 Mario Capecchi Drive,

Salt Lake City, UT 84I32, USA

Tel + I $80|58| 2352$

Fax + | 80I 58| 3357

Email majid.moshirfar@hsc.utah.edu
Purpose: To evaluate visual outcomes in moderately myopic eyes with flat and steep corneas (preoperatively) that have been treated with laser-assisted in situ keratomileusis (LASIK).

Patients and methods: Records of ninety-six eyes with average preoperative keratometry $(\mathrm{K})$ values between 39.9 and 42.0 diopters (D) (flat) were matched with 103 eyes with preoperative K values between 46.0 and 47.2 D (steep) that underwent LASIK between March 2007 and March 2010 for moderate myopia, and were retrospectively reviewed. The primary outcome measures used to determine the effect of preoperative keratometry on visual prognosis were refraction, visual acuity, change in keratometry $(\Delta K)$, and change in spherical equivalent $(\Delta S E)$, measured at 1, 3, 6, and 12 months postoperatively.

Results: Significant differences were found at 6 months postoperatively between the flat group and steep group in SE $(P=0.029)$, sphere $(P=0.018), \Delta \mathrm{K}(P=0.002)$, percentage of eyes achieving SE of -0.25 to $+0.25 \mathrm{D}(P=0.0125),-0.26$ to $-0.50 \mathrm{D}(P=0.003),-0.51$ to $-1.00 \mathrm{D}(P=0.044)$, and the percentage of eyes achieving uncorrected distance visual acuity of $20 / 15$ or better $(P=0.0006)$.

Conclusion: Moderately myopic eyes with flatter corneas preoperatively have better visual prognosis following LASIK compared with moderately myopic eyes with steeper corneas.

Keywords: keratometry, cornea, LASIK, refractive surgery

\section{Introduction}

The relationship between preoperative keratometry $(\mathrm{K})$ and visual outcomes in laser-assisted in situ keratomileusis (LASIK) has been studied in high myopia and hyperopia, but not in moderate myopia. Rao et al report increased undercorrection in eyes with preoperative spherical equivalent (SE) of -10.0 to -11.9 diopters (D), and in eyes with flat corneas compared with steeper corneas. ${ }^{1}$ Williams et al, conversely, reported undercorrection and loss of best spectacle corrected visual acuity (BSCVA) following hyperopic LASIK in eyes with steep corneas, compared with flat corneas. ${ }^{2}$ To our knowledge, to date no study has analyzed visual prognosis based on preoperative keratometry in moderately myopic LASIK. In this retrospective analysis, we studied the relationship between preoperative keratometry and postoperative visual outcomes in flat and steep corneas treated with LASIK for the correction of moderate myopia $(-2.00$ to $-5.99 \mathrm{D})$.

\section{Patients and methods}

From March 2007 to March 2010, a total of 1131 eyes underwent LASIK for the correction of moderate myopia at the John A Moran Eye Center, University of Utah. 
Of these, 96 eyes with average K of $39.9 \mathrm{D}$ to $42.0 \mathrm{D}$ (flat) were compared with 103 eyes with average K of $46.0 \mathrm{D}$ to 47.2 D (steep). All eyes had been targeted for emmetropia and treated with the VISX ${ }^{\mathrm{TM}}$ Star S4 CustomVue Excimer Laser System (Abbott Medical Optics Inc, Santa Ana, CA), had received no prior eye surgeries, and had received follow-up for at least 6 months. Eyes that had been classified as "high risk" or "moderate risk" (using Randleman's Ectasia Risk Factor Score System) were excluded, leaving only eyes classified as "low-risk" for ectasia. ${ }^{3}$

All eyes were stringently screened for keratoconus, and the presence of risk factors associated with forme fruste keratoconus, using slit-lamp examination, retinoscopy, topography, and Rabinowitz criteria. ${ }^{4-6}$ Additionally, all eyes were screened for asymmetry, non-orthogonal bowties, or skewed radial axes, with topographic analysis using the Orbscan ${ }^{\circledR}$ IIz (Bausch and Lomb, Rochester, NY). Corneal K values were measured using an Atlas $^{\mathrm{TM}}$ Corneal Topographer (Carl Zeiss Meditec Inc, Dublin, CA).

Eyes were placed into two groups based on preoperative average $\mathrm{K}$, where $\mathrm{K}_{\text {average }}=\left(\mathrm{K}_{\text {flat }}+\mathrm{K}_{\text {steep }}\right) / 2$. Eyes with average $\mathrm{K}$ values of $39.9 \mathrm{D}$ to $42.0 \mathrm{D}$ were placed in the "flat group" and eyes with average $\mathrm{K}$ values of $46.0 \mathrm{D}$ to $47.2 \mathrm{D}$ were placed in the "steep group." Eyes were matched according to preoperative age, SE, sphere, and cylinder. Residual stromal thickness (RST) was calculated by subtracting flap thickness and ablation depth from preoperative corneal thickness. Change in $\mathrm{K}(\Delta \mathrm{K})$ was calculated as preoperative minus postoperative average $\mathrm{K}$. Change in $\mathrm{SE}(\triangle \mathrm{SE})$ was calculated as postoperative SE minus preoperative SE. Table 1 shows the demographic and preoperative characteristics. Differences between the two groups were statistically evaluated using an independent Student's $t$-test of equal variance and a twosided $z$-test for proportions.

\section{Description of procedure}

LASIK was performed using standard protocol by two refractive eye surgeons at the Moran Eye Center, University of Utah. $\mathrm{K}$ readings were considered in the planning stage prior to surgery, and the same nomogram was used for all treatments. The residual stromal bed was planned to be $>260 \mu \mathrm{m}$ to avoid excessive corneal thinning associated with post-LASIK ectasia. Superior hinged lamellar flaps were created with a Hansatome Microkeratome (Bausch and Lomb Surgical, Rochester, NY) using a $160 \mu \mathrm{m}$ plate and $9.0 \mathrm{~mm}$ ring. Laser ablation was performed using the $\mathrm{VISX}^{\mathrm{TM}}$ Star S4 CustomVue system, creating a $6.5 \mathrm{~mm}$ optical zone with $8.0 \mathrm{~mm}$ blend zone. Following ablation, the flap was replaced and the patients then received fluoroquinolone and prednisolone acetate $1 \%$ drops. Standardized graphs were used to analyze accuracy, efficacy, safety, and stability. SE was measured at the spectacle plane. Uncorrected distance visual acuity (UDVA), corrected distance visual acuity (CDVA), and average $\mathrm{K}$ measurements were performed at 1, 3, 6, and 12 month postoperative visits. The primary endpoint reported in this study is 6 months postoperatively.

\section{Results}

Table 1 shows the preoperative patient characteristics by group. No statistically significant difference existed

Table I Demographic and preoperative characteristics

\begin{tabular}{|c|c|c|c|}
\hline Demographics & Flat & Steep & \\
\hline Patients (n) & 64 & 77 & \\
\hline Eyes (n) & 96 & 103 & \\
\hline Male:female & $2: 3$ & $3: 4$ & \\
\hline Preoperative characteristics & Mean \pm SD (range) & Mean \pm SD (range) & $P$-value \\
\hline Age $(y)$ & $37.9 \pm 9.3(23$ to 62$)$ & $39.0 \pm 8.6(22$ to 54$)$ & 0.387 \\
\hline Spherical equivalent (D) & $-3.61 \pm 0.99(-2.00$ to -5.75$)$ & $-3.76 \pm 1.12(-2.00$ to -5.875$)$ & 0.255 \\
\hline Sphere (D) & $-3.95 \pm 1.01(-2.25$ to -6.50$)$ & $-4.16 \pm 1.21(-2.25$ to -6.75$)$ & 0.182 \\
\hline Cylinder (D) & $0.66 \pm 0.56(0.00$ to 2.75$)$ & $0.76 \pm 0.73(0.00$ to 2.75$)$ & 0.307 \\
\hline Keratometry (D) & $41.4 \pm 0.50(39.9$ to 42.0$)$ & $46.5 \pm 0.33(46.0$ to 47.2$)$ & $4.46 \times 10^{-156}$ \\
\hline Pachymetry $(\mu \mathrm{m})$ & $557 \pm 29(507$ to 640$)$ & $555 \pm 32(500$ to 632$)$ & 0.653 \\
\hline Ablation depth $(\mu \mathrm{m})$ & $52 \pm 15(15$ to 89$)$ & $56 \pm 17(12$ to 93$)$ & 0.186 \\
\hline RST $(\mu \mathrm{m})$ & $336 \pm 4 I(274$ to 436$)$ & $336 \pm 44$ (278 to 448$)$ & 0.989 \\
\hline Low Randleman risk score (\%) & 100 & 100 & \\
\hline Rabinowitz criteria (\%) & 0 & 0 & \\
\hline
\end{tabular}

Notes: Values are calculated using homoscedastic independent Student's t-test; Low Randleman risk score: 0-2; Rabinowitz criteria: Keratometry > 47.2.

Abbreviations: SD, standard deviation; D, diopters; RST, residual stromal thickness. 
between the flat and steep matched cohort groups in mean preoperative age $(P=0.387)$, SE $(P=0.255)$, sphere $(P=0.182)$, cylinder $(P=0.307)$, pachymetry $(P=0.653)$, ablation depth $(P=0.186)$, or residual stromal thickness $(P=0.989)$. As expected, a significant difference was found between the flat and steep groups in mean preoperative $\mathrm{K}$ $\left(P=4.46 \times 10^{-156}\right)$.

Table 2 shows the outcomes measured at 6 months postoperatively. Significant differences were found between the flat and steep groups in SE $(P=0.029)$, sphere $(P=0.018), \mathrm{K}\left(P=1.21 \times 10^{-42}\right)$, and $\Delta \mathrm{K}(P=0.002)$. There was no statistically significant difference in cylinder $(P=0.294)$ or $\triangle \mathrm{SE}(P=0.823)$.

Figure 1 shows a stratification of eyes into the percentage of eyes achieving SE of -0.25 to $+0.25 \mathrm{D},-0.26$ to $-0.50 \mathrm{D}$, and -0.51 to $-1.00 \mathrm{D}$, measured at 6 months postoperatively. All three categories showed a statistically significant difference between the flat and steep groups. Seventy-five percent of eyes in the flat group achieved SE of -0.25 to $0.25 \mathrm{D}$, compared with $60 \%$ in the steep group $(P=0.0125)$. Four percent of eyes in the flat group achieved SE -0.50 to $-0.26 \mathrm{D}$, compared with $17 \%$ in the steep group $(P=0.003)$. Five percent of eyes in the flat group achieved SE of -0.51 to $-1.00 \mathrm{D}$, compared with $14 \%$ in the steep group $(P=0.044)$. A significant difference was also found in the percentage of eyes achieving UDVA of 20/15 or better (Figure 2), where $42 \%$ of eyes in the flat group achieved UDVA of $20 / 15$ or better, compared with $19 \%$ in the steep group $(P=0.001)$. No significant difference was found between the two groups in change in Snellen Lines of CDVA (Figure 3). In the flat and steep groups, respectively, $72 \%$ and $66 \%$ had $\leq 0.25 \mathrm{D}$ of refractive astigmatism (Figure 4). Five percent of eyes in the flat group and $2 \%$ of eyes in the steep group experienced a change in SE greater than $0.50 \mathrm{D}$ between 6 and 12 months postoperatively, though this difference was not significant (Figures 5 and 6).

\section{Discussion}

To the best of our knowledge, this is the first study to analyze visual outcomes in moderate myopia, comparing notably flat and steep preoperative keratometry using a matched cohort study design. The flat and steep groups were matched by age, preoperative SE, and preoperative cylinder, as well as having identical microkeratome models and excimer laser ablation platforms. The results suggest that moderately myopic eyes with flatter corneas have better visual outcomes than those with steeper corneas.

The clinical relevance of this study is best understood through comparison with the results of previous studies that examined eyes with high myopia and hyperopia. Our study, focusing on eyes with moderate myopia of -2.00 to $-5.99 \mathrm{D}$, contradicts the results of previous studies that examined eyes with high myopia prior to LASIK. ${ }^{1,7-13}$ Rao et al found that eight eyes with $\mathrm{K}<43.5 \mathrm{D}$ and myopia of -10.0 to $-11.9 \mathrm{D}$ had a 3-month SE that was significantly different compared with sixteen eyes with $\mathrm{K}>44.5$ and similarly high myopia. They also suggested a trend toward undercorrection, though the trend was not statistically significant and had an $r^{2}$ value of just $0.03 .{ }^{1}$ Perez-Santonja et al also reported a tendency toward undercorrection in eyes with flatter corneas that had received LASIK for the correction of high myopia of -8.00 to $-20.00 \mathrm{D}^{7}$ This study differs from the two studies mentioned above, because it examined a greater sample of eyes, including eyes with moderate myopia of -2.00 to -5.99 D. Several authors have found that, after myopic procedures, induced spherical aberrations tend to be positive and correlated with the magnitude of the intended correction. They have also made the observation that corneal asphericity, tissue removal, and tissue remodeling have made it difficult to establish an optimum profile. In our study, however, $\Delta \mathrm{SE}$ was similar in the flat and steep groups. Thus, our findings are unlikely to be explained solely by tissue remodeling,

Table 2 Outcomes at 6 months postoperatively

\begin{tabular}{|c|c|c|c|}
\hline & Flat & Steep & P-value \\
\hline & Mean \pm SD (range) & Mean \pm SD (range) & \\
\hline Spherical Equivalent (D) & $-0.10 \pm 0.45(-1.63$ to 1.00$)$ & $-0.23 \pm 0.43(-1.75$ to 0.75$)$ & 0.029 \\
\hline Sphere (D) & $-0.21 \pm 0.47(-1.75$ to 0.75$)$ & $-0.37 \pm 0.47(-2.00$ to 0.50$)$ & 0.018 \\
\hline Cylinder (D) & $0.23 \pm 0.27$ (0.00 to I.25) & $0.27 \pm 0.30(0.00$ to 1.25$)$ & 0.294 \\
\hline Keratometry (D) & $38.90 \pm 1 . I I(36.00$ to $4 I .19)$ & $43.30 \pm 1.08(4 I .31$ to 46.19$)$ & $1.21 \times 10^{-42}$ \\
\hline$\Delta \mathrm{K}(\mathrm{D})$ & $2.55 \pm \mathrm{I} . \mathrm{II}(0.45$ to 5.25$)$ & $3.17 \pm 0.96(0.97$ to 4.94$)$ & 0.002 \\
\hline$\Delta S E(D)$ & $3.52 \pm 1.13(1.25$ to 6.125$)$ & $3.55 \pm 1.15(0.75$ to 6.13$)$ & 0.823 \\
\hline
\end{tabular}

Note: Values are calculated using homoscedastic independent Student's $t$-test.

Abbreviations: $\mathrm{SD}$, standard deviation; $\mathrm{K}$, keratometry; D, diopters; $\mathrm{SE}$, spherical equivalent; $\Delta \mathrm{K}, \mathrm{K}_{\text {avg(preop) }}-\mathrm{K}_{\text {avg(postop) }} ; \Delta \mathrm{SE}, \mathrm{SE} \mathrm{postop}-\mathrm{SE}_{\text {preop }}$ 


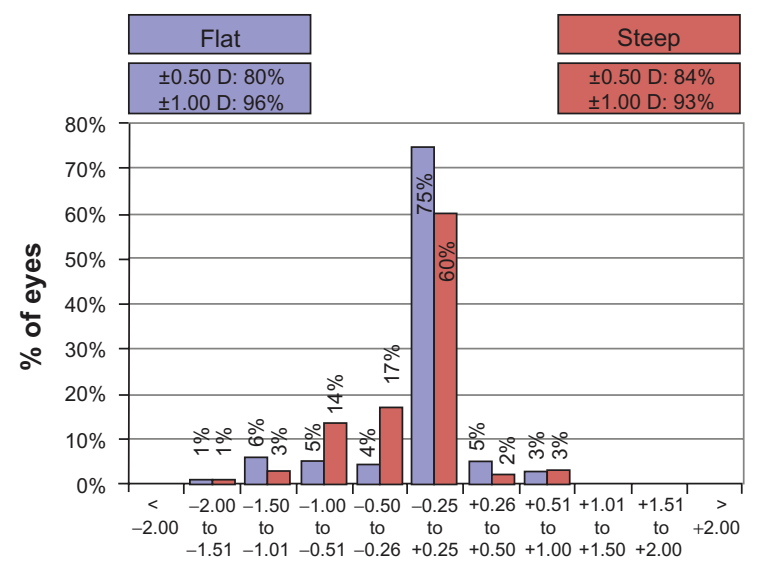

Postoperative spherical equivalent refraction (D)

Figure I Distribution of postoperative SE refraction, with a higher percentage of eyes being closer to plano in the flat group than in the steep group.

Abbreviation: D, diopters.

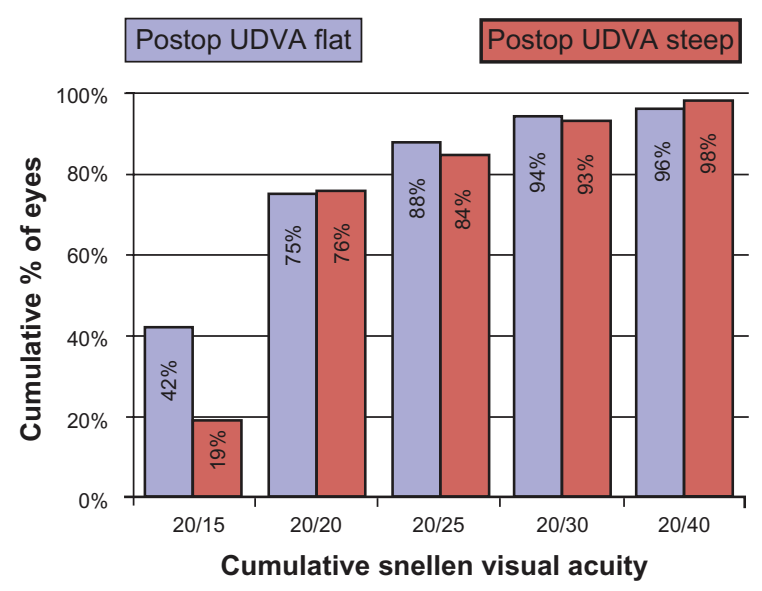

Figure 2 Postoperative visual acuity.

Note: More eyes achieved UDVA of 20/15 in the flat group than in the steep group.

Abbreviation: UDVA, uncorrected distance visual acuity.

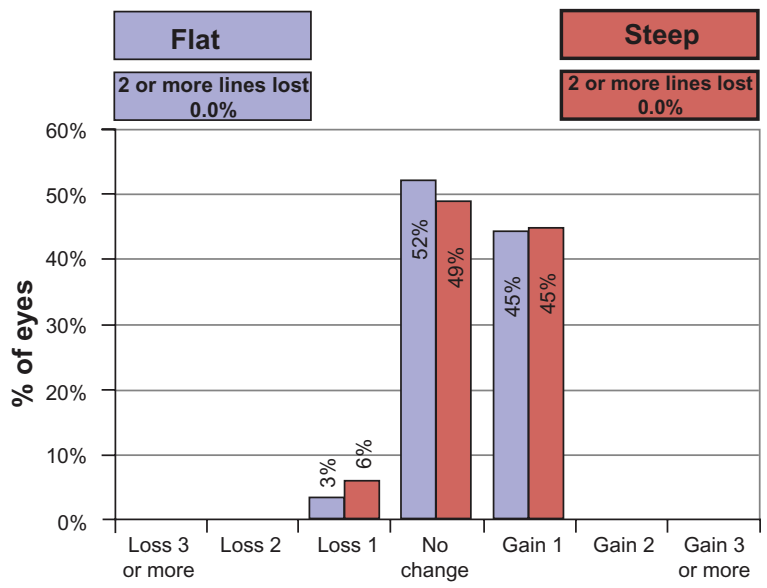

Change in snellen lines of CDVA

Figure 3 Number of lines of CDVA lost or gained after surgery between the flat and steep groups.

Abbreviation: CVDA, corrected distance visual acuity.

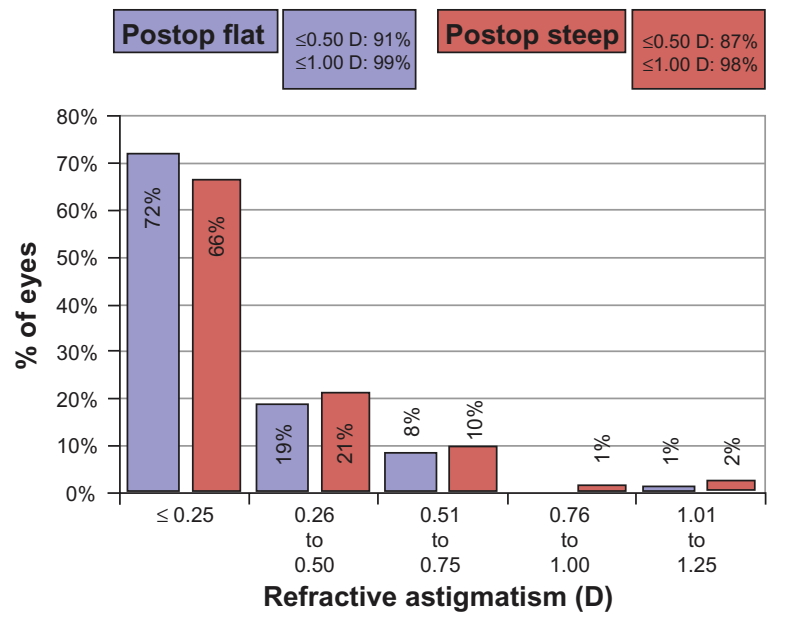

Figure 4 Postoperative refractive astigmatism with the majority of eyes in each group achieving $\leq 0.25$ diopters of astigmatism.

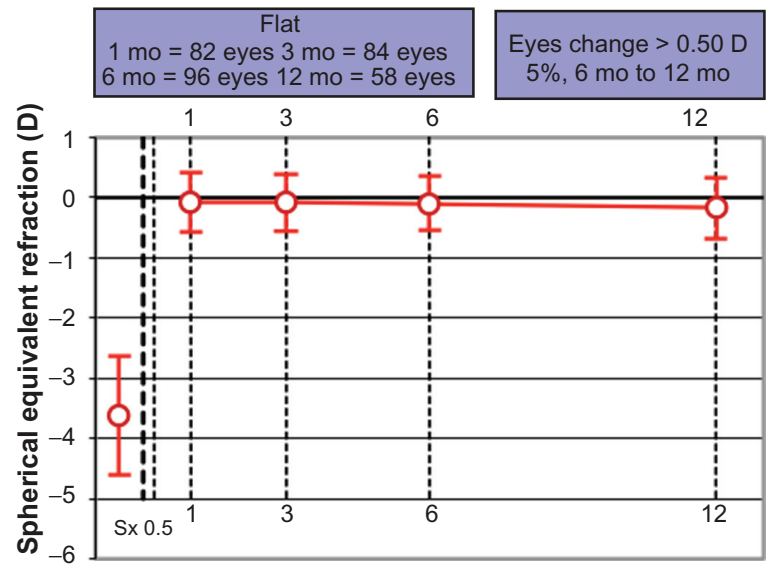

Time after surgery (months)

Figure 5 Flat group demonstrating small changes in postoperative SE refraction over 12 months.

Abbreviation: SE, spherical equivalent.

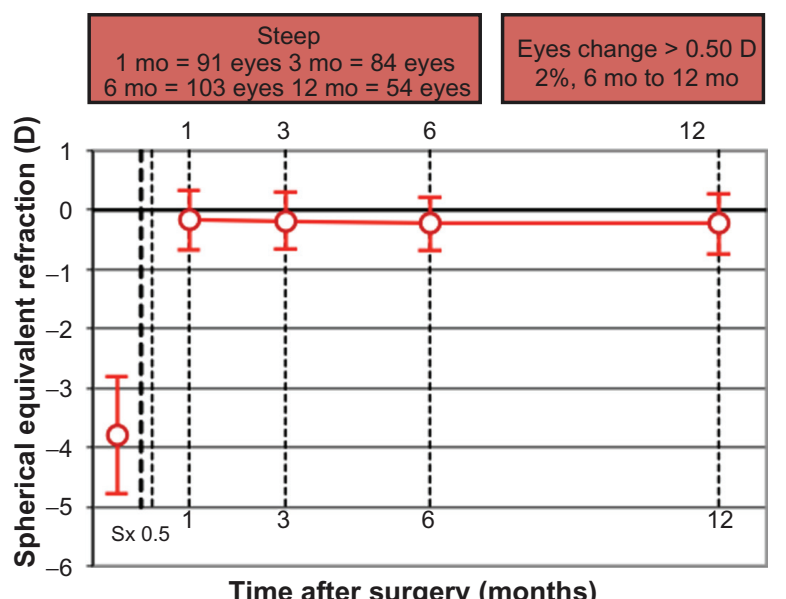

Figure 6 The steep group, demonstrating small changes in postoperative SE refraction over 12 months.

Abbreviation: SE, spherical equivalent. 
corneal asphericity, and spherical aberration, which may occur secondarily to ablation efficiency reduction. ${ }^{14-19}$

Two other studies, although they examine hyperopic LASIK, coincide with our results. Williams et al prospectively examined 6-month follow-up data and found an increased incidence of loss of BSCVA with eyes that had preoperative $\mathrm{K}>44.0 \mathrm{D}$. $^{2}$ Esquenazi et al found that undercorrection occurred more frequently in eyes with preoperative $\mathrm{K}>45.0$ D. ${ }^{20}$ Furthermore, several studies have examined the effect of preoperative $\mathrm{K}$ on outcomes in surface ablation. However, these results should be cautiously applied to LASIK, because the flap created causes changes in the cornea that are not present in surface ablation techniques. ${ }^{3,21}$ The flap can vary in size depending on preoperative keratometry, and by itself can induce astigmatism or hyperopia, depending on hinge position and depth of stromal involvement. .2,23 $^{22}$

A weakness of our study is that it is retrospective and that RST was calculated instead of being measured intraoperatively, which could have affected calculations for Randleman's criteria. It is also possible that eyes in the steep group were subject to subclinical keratectasia not seen in evaluation of preoperative topography, thus providing a possible explanation for suboptimal outcomes in comparison to eyes in the flat group. However, screening with the use of Rabinowitz's criteria, ideally, eliminated eyes with forme fruste keratoconus. Furthermore, our findings were consistent with those of Ortega-Usobiaga et al, who found no post-LASIK ectasia among eyes with steep corneas preoperatively. ${ }^{24}$ Applying Randleman's Ectasia Risk Factor Score System demonstrated that all eyes in each group were classified as low-risk for ectasia and did not meet Rabinowitz's criteria for forme fruste keratoconus (Table 1). However, despite our efforts to screen for ectasia-risk, the possibility remains of subclinical and subtopographical keratectasia characteristics in the eyes with steep corneas, which could manifest at a follow-up time of greater than 12 months.

\section{Conclusion}

Moderately myopic eyes with flatter corneas tend to have better visual outcomes after LASIK than those with steeper corneas. Further studies should be performed to better define the effect that keratometry has on LASIK outcomes at varying levels of preoperative refraction. The findings of this study will assist surgeons to better predict prognosis in eyes with $\mathrm{K}$ of 39.9 to $42.0 \mathrm{D}$, which may previously have been found ineligible for moderate myopic LASIK, and also to consider more aggressive laser ablation in eyes with $\mathrm{K}$ of 46.0 to $47.2 \mathrm{D}$, so as to avoid the undercorrection described in this study. At present, many refractive surgeons use nomograms that do not include preoperative $\mathrm{K}$ values to calculate postoperative refraction. We suggest that preoperative $\mathrm{K}$ should be one of the featured factors in pre-treatment nomogram calculation.

\section{Acknowledgment}

Funding has been provided by the Research to Prevent Blindness Foundation, New York, NY.

\section{Disclosure}

The authors have no financial interests in any materials or products discussed in this manuscript, or any other disclosures.

\section{References}

1. Rao SK, Cheng AC, Fan DS, Leung AT, Lam DS. Effect of preoperative keratometry on refractive outcomes after laser in situ keratomileusis. $J$ Cataract Refract Surg. 2001;27(2):297-302.

2. Williams LB, Dave SB, Moshirfar M. Correlation of visual outcome and patient satisfaction with preoperative keratometry after hyperopic laser in situ keratomileusis. J Cataract Refract Surg. 2008;34(7): 1083-1088.

3. Randleman JB, Ward MA, Lynn MJ, Stulting RD. Risk assessment for ectasia after corneal refractive surgery. Ophthalmology. 2008;115(1): $37-50$.

4. Binder PS, Lindstrom RL, Stulting RD, et al. Keratoconus and corneal ectasia after LASIK. J Cataract Refract Surg. 2005;31(11): 2035-2038.

5. Rabinowitz YS, McDonnell PJ. Computer-assisted corneal topography in keratoconus. Refract Corneal Surg. 1989;5(6):400-408.

6. Rabinowitz TS. Videokeratographic indices to aid in screening for keratoconus. J Refract Surg. 1995;11(5):371-379.

7. Perez-Santonja JJ, Bellot J, Claramonte P, Ismail MM, Alió JL. Laser in situ keratomileusis to correct high myopia. J Cataract Refract Surg. 1997;23(3):372-385.

8. Vajpayee RB, Ghate D, Sharma N, Tandon R, Titiyal JS, Pandey RM. Risk factors for postoperative cylindrical prediction error after laser in situ keratomileusis for myopia and myopic astigmatism. Eye (Lond). 2008;22(3):332-339.

9. Hu DJ, Feder RS, Basti S, Fung BB. Predictive formula for calculating the probability of LASIK enhancement. J Cataract Refract Surg. 2004;30(2):363-368.

10. Ditzen K, Huschka H, Pieger S. Laser in situ keratomileusis for hyperopia. J Cataract Refract Surg. 1998;24(1):42-47.

11. Young JJ, Schallhorn SC, Brown MC, Hettinger KA. Effect of keratometry on visual outcomes 1 month after hyperopic LASIK. J Refract Surg. 2009;25(7):S672-S676.

12. Cobo-Soriano R, Llovet F, Gonzalez-Lopez F, Domingo B, Gomez-Sanz F, Baviera J. Factors that influence outcomes of hyperopic laser in situ keratomileusis. J Cataract Refract Surg. 2002;28(9): $1530-1538$.

13. Tabbara KF, El-SheikhHF, Islam SMM. Laser in situ keratomileusis for the correction of hyperopia from +0.5 to +11.50 diopters with the Keracor 117C laser. J Refract Surg. 2001;17(2):123-128.

14. Kwon Y, Bott S. Postsurgery corneal asphericity and spherical aberration due to ablation efficiency reduction and corneal remodelling in refractive surgeries. Eye. 2009;23(9):1845-1850. 
15. Schwiegerling J, Snyder RW. Corneal ablation patterns to correct for spherical aberration in photorefractive keratectomy. J Cataract Refract Surg. 2000;26(2):214-221.

16. Marcos S, Cano D, Barbero S. Increase in corneal asphericity after standard laser in situ keratomileusis for myopia is not inherent to the munnerlyn algorithm. J Refract Surg. 2003;19(5):S592-S596.

17. Hersh PS, Fry K, Blaker JW. Spherical aberration after laser in situ keratomileusis and photorefractive keratectomy clinical results and theoretical models of etiology. J Cataract Refract Surg. 2003;29(11): 2096-2104.

18. Yoon G, MacRae S, Williams DR, Cox IG. Causes of spherical aberration induced by laser refractive surgery. J Cataract Refract Surg. 2005;31(1):127-135.

19. Arba Mosquera S, de Ortueta D. Analysis of optimized profiles for 'aberration-free' refractive surgery. Ophthalmic Physiol Opt. 2009; 29(5):535-548.
20. Esquenazi S, Mendoza A. Two-year follow-up of laser in situ keratomileusis for hyperopia. J Refract Surg. 1999;15(6):648-652.

21. Blaker JW, Hersh PS. Theoretical and clinical effect of preoperative corneal curvature on excimer laser photorefractive keratectomy for myopia. J Refract Corneal Surg. 1994;10(5):571-574.

22. Albelda-Vallés JC, Martin-Reyes C, Ramos F, Beltran J, Llovet F, Baviera J. Effect of preoperative keratometric power on intraoperative complications in LASIK in 34,099 eyes. J Refract Surg. 2007;23(6): 592-597.

23. Dupps WJ Jr, Wilson SE. Biomechanics and wound healing in the cornea. Exp Eye Res. 2006;83(4):709-720.

24. Ortega-Usobiaga J, Martin-Reyes C, Llovet-Usuna F, Beltran-Sanz J, Caro M, Baviera-Sabater J. Myopic LASIK and LASEK in patients with preoperative mean central keratometry $\geq 47.50$ D. J Refract Surg. 2011;27(8):591-596
Clinical Ophthalmology

\section{Publish your work in this journal}

Clinical Ophthalmology is an international, peer-reviewed journal covering all subspecialties within ophthalmology. Key topics include: Optometry; Visual science; Pharmacology and drug therapy in eye diseases; Basic Sciences; Primary and Secondary eye care; Patient Safety and Quality of Care Improvements. This journal is indexed on

\footnotetext{
Submit your manuscript here: http://www.dovepress.com/clinical-ophthalmology-journal
}

\section{Dovepress}

PubMed Central and CAS, and is the official journal of The Society of Clinical Ophthalmology (SCO). The manuscript management system is completely online and includes a very quick and fair peer-review system, which is all easy to use. Visit http://www.dovepress.com/ testimonials.php to read real quotes from published authors. 